Research Paper

\title{
Essential oils of thyme and Rosemary in the control of Listeria monocytogenes in raw beef
}

\author{
Maíra Maciel Mattos de Oliveira ${ }^{1}$, Danilo Florisvaldo Brugnera ${ }^{2}$, \\ Roberta Hilsdorf Piccoli ${ }^{3}$ \\ Instituto Federal de Educação, Ciência e Tecnologia do Espírito Santo, Campus Venda Nova do \\ Imigrante, Venda Nova do Imigrante, ES, Brazil. \\ Universidade Federal de Mato Grosso, Faculdade de Nutrição, Cuiabá, MT, Brazil. \\ Universidade Federal de Lavras, Departamento de Ciência dos Alimentos, \\ Laboratório de Microbiologia dos Alimentos, Lavras, MG, Brazil.
}

Submitted: August 3, 2011; Approved: April 4, 2013.

\begin{abstract}
This study was developed in order to evaluate two alternatives for the control of Listeria monocytogenes in raw bovine meat pieces, both based on the use of Thymus vulgaris and Rosmarinus officinalis essential oils (EOs). The antilisterial activity of different concentrations of the EOs was tested in vitro using agar dilution and disk volatilization techniques. In addition, L. monocytogenes was inoculated in meat pieces, which were submerged in edible gelatin coatings containing $2 \%(\mathrm{v} / \mathrm{v})$ EOs or submitted to the vapor of EOs $\left(0.74 \mu \mathrm{L} . \mathrm{cm}^{-3}\right)$. L. monocytogenes was quantified after one, 48 and 96 hours of storage $\left(7^{\circ} \mathrm{C}\right)$. In the in vitro tests, the $\mathrm{EO}$ of $T$. vulgaris presented higher activity. The two options used (edible gelatin coating and vapor activity), in spite of exercising effects with differentiated behaviors, presented antibacterial activity against $L$. monocytogenes inoculated in raw bovine meat $(\mathrm{p}<0.05)$. Greatest antibacterial activity were obtained in the experiment that used edible coatings containing EOs, at 48 hours of storage reductions in bacterial counts between 1.09 and 1.25 Log CFU.g ${ }^{-1}$ were obtained. In the vapor effect experiment, the EO of T. vulgaris caused the highest reduction in the population of bacteria inoculated in raw bovine meat $(p<0.05), 0.40 \mathrm{Log}$ $\mathrm{CFU} . \mathrm{g}^{-1}$ at 96 hours of storage. This study supplied important information regarding new and promising natural alternatives, based on the concept of active packaging, for the control of L. monocytogenes in the meat industry.
\end{abstract}

Key words: Thymus vulgaris, Rosmarinus officinalis, antilisterial compounds, active packaging, meat safety.

\section{Introduction}

The contamination of ready-to-eat (RTE) foods, especially meat products, with $L$. monocytogenes has been related as a serious public health problem (Sofos, 2008; Mor-Mur and Yuste, 2010). However, another fact that deserves equal attention is the presence of this pathogenic bacterium in raw bovine meat, which has already been reported in some recent studies (Chen et al., 2009; Karakolev, 2009; Pesavento et al., 2010). These facts demonstrate the presence of L. monocytogenes in the meat chain and em- phasize that, besides good manufacturing practices, control alternatives should be development.

Several alternatives are available for the control of microorganisms in the food industry. One of them is the use of active packaging with antimicrobial effects, such as the surface application of coatings and edible films elaborated with proteins, polysaccharides or lipids, and the liberation of volatile compounds in the atmosphere surrounding the food (Devlieghere et al., 2004; Bourtoom, 2008; Ustunol, 2009). This control options are extremely effective in the case of foods with mostly surface microbiological contami- 
nation, such as raw bovine meats marketed as steaks or in various sized pieces.

Also, in this context, there is an increasing demand for safe and natural foods without the addition of chemical preservatives, which has been motivating research on the antimicrobial effects of plant derivatives (Dimitrijevic et al., 2007). An example of those substances is the essential oils (EOs), known for presenting biological activity, especially antibacterial, antifungal and antioxidant properties (Burt, 2004; Tajkarimi et al., 2010). The antilisterial activity of different EOs was demonstrated in vitro in some recent studies. Oliveira et al. (2012) verified that the EOs of Cinnamomum cassia (Chinese cinnamon), Melaleuca alternifolia (tea tree) and Cymbopogon flexuosus (lemongrass) were effective against L. monocytogenes ATCC 19117 inoculated in agar and broth culture medium. Andrade et al. (2012) and Millezi et al. (2012), studying the same strain of L. monocytogenes, verified, respectively, that the EOs of Cymbopogon nardus (citronella), Cinnamomum zeylanicum (cinnamon) and Zingiber officinale (ginger), and the EOs of Thymus vulgaris (thyme), Cymbopogon citratus (lemongrass) and Laurus nobilis (bay), presented antilisterial activity.

Interesting alternatives to control L. monocytogenes are the EOs of T. vulgaris and Rosmarinus officinalis (rosemary), spices that are used to provide flavor to foods, such as meats and their derivatives. The antilisterial activity of these EOs has already been demonstrated in vitro (Pandit and Shelef, 1994; Dimitrijevic et al., 2007; Singh et al., 2003; Solomakos, 2008), as well as in food products, such as pork liver sausage (Pandit and Shelef, 1994), hotdogs (Singh et al., 2003)and minced beef meat (Solomakos et al., 2008).

This study was developed with the intention of evaluating two new alternatives for the control of L. monocytogenes in raw bovine meat pieces, both based on the use of $T$. vulgaris and $R$. officinalis EOs as antibacterial agents: the submission to their vapors and the application of edible gelatin coatings.

\section{Material and Methods}

\section{Microorganism used, standardization, inoculum preparation and storage}

The microorganism used was L. monocytogenes ATCC 19117, acquired from the Culture Collection Section of the Medical Biology Division of the Adolfo Lutz Institute (São Paulo, SP, Brazil). For standardization, inoculum preparation and storage were followed the procedures previously described by Oliveira et al. (2010a, 2010b).

\section{EOs}

EOs of leaves and flowers of $T$. vulgaris and leaves of $R$. officinalis were acquired from Ferquima Indústria e Comércio Ltda. (Vargem Grande Paulista, SP, Brazil).

\section{Chemical composition}

A gas chromatography (GC) apparatus coupled to a mass spectrometry (MS) apparatus (GCMS-QP 2010 Plus, Shimadzu) was used. The EOs, diluted in dichloromethane, were injected with a AOC-5000 Auto Injector (Shimadzu). The chromatographic conditions were the following: column oven temperature $40^{\circ} \mathrm{C}$, injection temperature $220^{\circ} \mathrm{C}$, splitless injection mode, sampling time $0.50 \mathrm{~min}$, He carrier gas, pressure $60.2 \mathrm{Kpa}$, total flow $14 \mathrm{~mL} \cdot \mathrm{min}^{-1}$, column flow $1 \mathrm{~mL} \cdot \mathrm{min}^{-1}$, linear velocity $36.1 \mathrm{~cm} . \mathrm{s}^{-1}$, purge flow $3 \mathrm{~mL} \cdot \mathrm{min}^{-1}$, split ratio 10.0 , total program time $54.50 \mathrm{~min}$, column Equity-5 (30 m x $0.25 \mathrm{~mm}$ x $0.25 \mu \mathrm{m}$ ), ion source temperature $200{ }^{\circ} \mathrm{C}$, interface temperature $250{ }^{\circ} \mathrm{C}$ and solvent cut time $4 \mathrm{~min}$. The components were identified by comparing their mass spectra and retention times with those available in the Wiley 8 Library and Flavour and Fragrance Natural and Synthetic Compounds (FFNSC) 1.2 Library. The percentage of each component was obtained by integrating the peak area.

\section{Antilisterial activity of EOs in culture medium}

\section{Dilution in agar}

EOs were homogenized in Trypic Soy Agar (TSA) (Himedia ${ }^{\circledR}$, Mumbai, Maharashtra, India) supplemented with $0.6 \%(\mathrm{w} / \mathrm{v})$ yeast extract (Himedia ${ }^{\circledR}$, Mumbai, Maharashtra, India) (TSA-YE) and containing $0.5 \%(\mathrm{v} / \mathrm{v})$ Tween 80 (Vetec, Duque de Caxias, RJ, Brazil) to obtain the following concentrations: $0.00,0.03,0.06,0.12,0.25,0.50$, 1.00 and $2.00 \%(\mathrm{v} / \mathrm{v})$. The culture medium containing EOs $(8 \mathrm{~mL})$ was distributed in Petri dishes (50 $\mathrm{mm}$ diameter), and three repetitions were conducted. Aliquots $(40 \mu \mathrm{L})$ of Trypic Soy Broth (TSB) (Himedia ${ }^{\circledR}$, Mumbai, Maharashtra, India) containing 8 Log CFU.mL ${ }^{-1}$ of L. monocytogenes were inoculated on the surface of the culture medium and spread with a Drigalski spatula. The incubation was performed at $37{ }^{\circ} \mathrm{C} / 24$ hours. The lowest concentrations that resulted in complete inhibition of the bacterial growth were called Minimum Inhibitory Concentrations (MICs) (Oliveira et al., 2012).

\section{Disk volatilization}

Filter paper discs (30 $\mathrm{mm}$ diameter) were fastened in the center of the lower part of the cover of glass Petri dishes (90 x $16 \mathrm{~mm}$ ), which contained $20 \mathrm{~mL}$ of TSA-YE, with the aid of double-faced adhesive tape. The distance between the surface of the culture medium and the disc was $13 \mathrm{~mm}$. EOs were added to the discs at concentrations of $0.18,0.36$, 0.54 and $0.72 \mu \mathrm{L} . \mathrm{cm}^{-3}$. At the highest concentration, the EO was used pure $(60 \mu \mathrm{L})$; for the other concentrations, the EO 
was diluted in ethanol: $0.18 \mu \mathrm{L} \cdot \mathrm{cm}^{-3}(15 \mu \mathrm{L}$ of EO and $45 \mu \mathrm{L}$ of ethanol); $0.36 \mu \mathrm{L} . \mathrm{cm}^{-3}$ ( $30 \mu \mathrm{L}$ of EO and $30 \mu \mathrm{L}$ of ethanol); and $0.54 \mu \mathrm{L} \cdot \mathrm{cm}^{-3}$ (45 $\mu \mathrm{L}$ of EO and $15 \mu \mathrm{L}$ of ethanol). A Petri dish with a filter paper disc containing only ethanol $(60 \mu \mathrm{L})$ and a Petri dish without filter paper disc were also used. TSB-YE, containing 8 Log CFU.mL ${ }^{-1}$ of $L$. monocytogenes, was inoculated $(100 \mu \mathrm{L})$ on the culture medium and spread with a Drigalski spatula. The Petri dishes were sealed with Polyvinyl Chloride (PVC) plastic film and incubated $\left(37^{\circ} \mathrm{C} / 24\right.$ hours). The diameter of the inhibition zones were measured using a digital caliper rule, acquiring the average of two diametrically opposed measurements. This methodology was adapted from López et al. $(2005,2007)$ and Nedorostova et al. (2009).

\section{Antilisterial activity of EOs in raw beef}

\section{Acquisition and preparation of beef}

The raw bovine meat (Quadriceps femoris) was acquired commercially vacuum packed wrapped. To reduce the accompanying microbiota, a layer of approximately $1 \mathrm{~cm}$ of meat was removed from the external surface of each piece.

\section{Edible gelatin coating}

For bacterial inoculation, meat pieces $(5 \times 5 \times 2.5 \mathrm{~cm}$ and, approximately, $50 \mathrm{~g}$ ) were submerged in TSB, containing $8 \mathrm{Log}$ cfu. $\mathrm{mL}^{-1}$ of L. monocytogenes, for ten minutes (Figure 1A) and, subsequently immediately,air-dried for one hour suspended by a support (adapted from 20). For the air-dried step, the meat pieces were fixed to hooks that were fastened to wires, both of stainless steel (Figure 1B).

Two coatings containing EOs were elaborated: CT, for T. vulgaris $\mathrm{EO}$; and $\mathrm{CR}$, for R. officinalis $\mathrm{EO}$. A coating without the addition of EOs was also used, and was called CW.

In the Table 1 are the edible coatings solutions formulations. To the solutions preparation were followed the procedures described below. The powdered edible gelatin $(24 \mathrm{~g})$ was added slowly, under agitation, in the smallest volume of sterile distilled water $(50 \mathrm{~mL}$ for $\mathrm{CT}$ and $\mathrm{CR}$, and $70 \mathrm{~mL}$ for $\mathrm{CW}$ ), called part $\mathrm{A}$. The mixture was microwaved until completely dissolved (1-2 min). The gelatin had a bloom of 240 and was manufactured by Gelco Gelatinas do Brasil Ltda. Fábrica de Conservas for Kraft Foods Brasil S.A. (Pedreira, SP, Brazil). EOs $(20 \mathrm{~mL})$, when used, were added to $30 \mathrm{~mL}$ of a Tween 80 solution $(25 \% \mathrm{v} / \mathrm{v}$ in distilled sterile water) and homogenized by vigorous agitation. The final percentage of EO in CT and CR was $2 \%$ $(\mathrm{v} / \mathrm{v})$. Finally, all the components mentioned above were added, together with $900 \mathrm{~mL}$ of sterile distilled water (part B), to one container and homogenized slightly for the elaboration of the coatings solutions, that presented a final volume of $1000 \mathrm{~mL}$ (Figure 1C).
$\mathrm{CT}$ and $\mathrm{CR}$ contained the highest concentration of EOs that was tested in vitro $(2 \% \mathrm{v} / \mathrm{v})$ because previous tests demonstrated that the MICs founded by the agar dilution method did not presented antilisterial effect when used in gelatin coatings applied over raw bovine meat.

For the coatings application, the meat pieces were submerged in the solutions presents in Table 1 for ten seconds and, subsequently immediately, air-dried for ten minutes (adapted from 20) (Figure 1D).

Additionally, the following treatment was elaborated: meat pieces inoculated with $L$. monocytogenes and not submitted to coatings application. This treatment was called WC.

The meat pieces were conditioned in cylindrical polyethylene terephthalate (PET) packaging ( $85 \mathrm{x} 43 \mathrm{~mm}$ internal dimensions, $170 \mathrm{~mL}$ capacity, transparent) (Figure 1E), that were wrapped in plastic film (PVC) and stored at $7{ }^{\circ} \mathrm{C}$.

\section{Vapor activity}

Meat pieces were cut $(6 \times 6 \times 0.6 \mathrm{~cm}$, approximately $30 \mathrm{~g})$ and put in Petri dishes $(90 \times 16 \mathrm{~mm})$ that contained filter paper discs (30 $\mathrm{mm}$ diameter) fastened to the central internal part of the dish covers with the aid of double-faced adhesive tape. For inoculation, that was conducted immediately after placing the meat pieces inside the Petri dishes, $100 \mu \mathrm{L}$ of peptone water $0.1 \%(\mathrm{w} / \mathrm{v})$ containing $5 \mathrm{Log}$ CFU.mL $\mathrm{m}^{-1}$ of L. monocytogenes was added in the center of the surface of the meat pieces with the aid of Drigalski spatulas. Pure EOs $(60 \mu \mathrm{L})$ were added to the filter paper discs at a concentration of $0.74 \mu \mathrm{L} . \mathrm{cm}^{-3}$.

The meat pieces were submitted to EOs only at the concentration of $0.74 \mu \mathrm{L} . \mathrm{cm}^{-3}$, because it was similar to the highest concentration used in the disc volatilization $\left(0.72 \mu \mathrm{L} . \mathrm{cm}^{-3}\right)$, and because previous tests demonstrated that the other concentrations $\left(0.18,0.36\right.$ and $\left.0.54 \mu \mathrm{L} . \mathrm{cm}^{-3}\right)$ that were used in vitro did not inhibit the bacterium in the meat.

A treatment composed of meat pieces put in Petri dishes without filter paper discs with EOs was used also. The Petri dishes were sealed with plastic film (PVC) and stored $\left(7^{\circ} \mathrm{C}\right)$.

The treatments were denominated: VT, when the meat was submitted to EO of T. vulgaris; VR, when it was submitted to EO of $R$. officinalis; and WV, when no EO was applied.

\section{Quantification of Listeria monocytogenes}

The analyses were conducted after one, 48 and 96 hours. For the coating evaluation experiment, $25 \mathrm{~g}$ of meat was added to $225 \mathrm{~mL}$ peptone water. For vapor activity, $10 \mathrm{~g}$ was added in $90 \mathrm{~mL}$ peptone water. The homogenization was conducted in Stomacher (490 strokes/minute for two minutes). Aliquots of $1 \mathrm{~mL}$ were removed, and serial decimal dilutions were performed in $9 \mathrm{~mL}$ of peptone water $0.1 \%(\mathrm{w} / \mathrm{v})$. Surface plating was performed on Oxford agar 

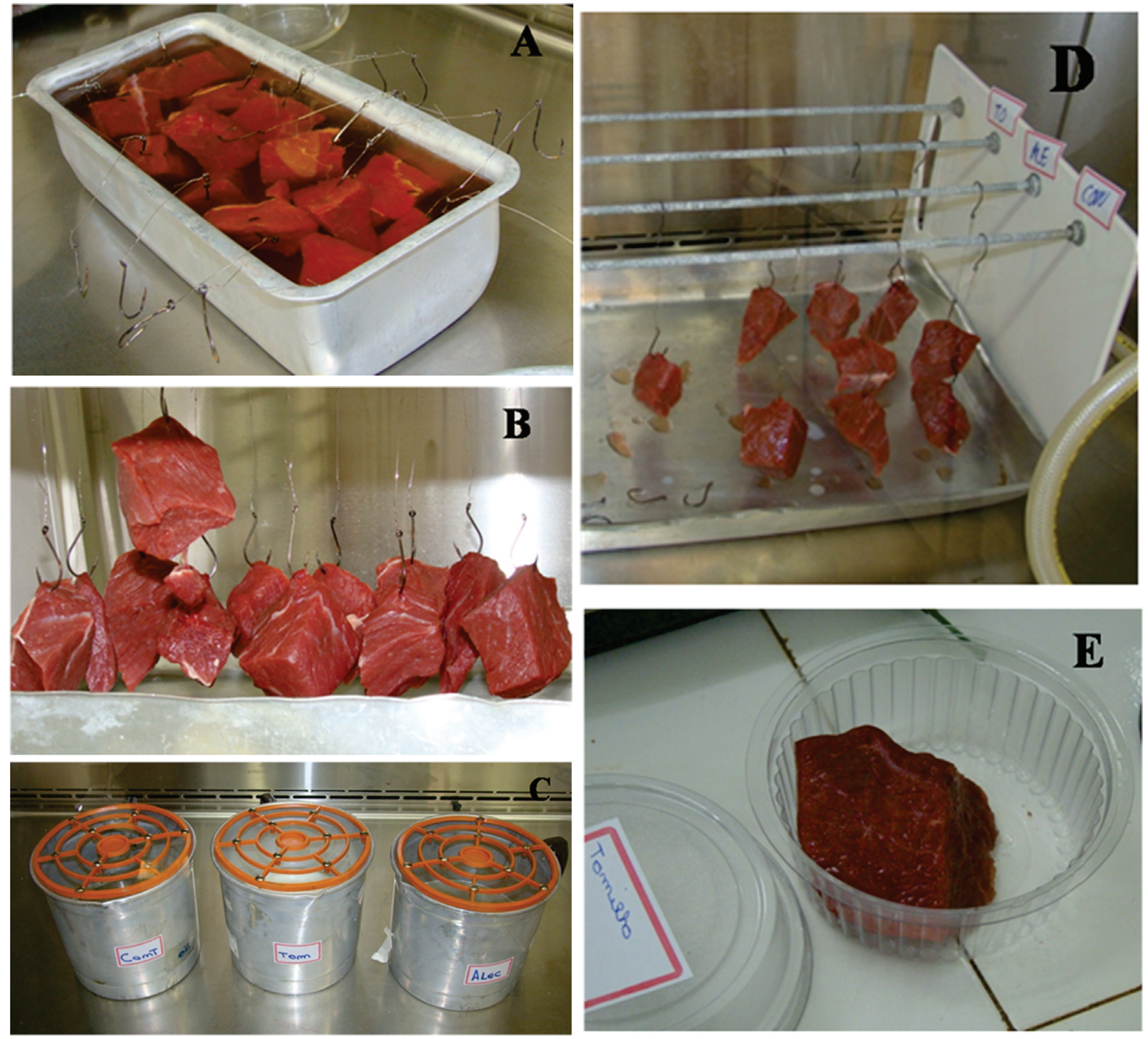

Figure 1 - Main stages of the experiment that evaluated the antibacterial activity of edible gelatin coatings containing essential oils (EOs) of Thymus vulgaris and Rosmarinus officinalis against Listeria monocytogenes inoculated in raw beef pieces. (A) L. monocytogenes inoculation in raw beef pieces. (B) Drying of the raw beef pieces after the bacterial inoculation step. (C) Recipients containing the edible coating solutions of gelatin, from left to right: solution without the addition of EOs, solution containing T. vulgaris EO, solution containing $R$. officinalis $\mathrm{EO}$. (D) Drying of the raw beef pieces after the edible coating application. (E) Raw beef piece with the application of edible gelatin coating containing $T$. vulgaris EO inside a polyethylene terephthalate packaging, after 1 hour storage at $7{ }^{\circ} \mathrm{C}$.

(Himedia ${ }^{\circledR}$, Mumbai, Maharashtra, India), and the incubation was conducted at $37^{\circ} \mathrm{C} / 24$ hours.

\section{Experimental designs and statistical analyses}

For the disc volatilization stage, a Completely Randomized Design (CRD) was used with three repetitions. When detected significant differences in the variance analysis, regression testing was performed.

For the coating experiments, a CRD was used, with four repetitions, in a $4 \times 3$ factorial outline (four applied meat treatments and three storage times). When significant differences in the variance analysis were detected, the Scott-knott test on the qualitative values and regression testing on the quantitative values were performed.
For the determination of vapor activity, a CRD was used, with four repetitions, in a $3 \times 3$ factorial outline (three applied meat treatments and three storage times). When significant differences in the variance analysis were detected, the Scott-knott test on the qualitative values and regression testing on the quantitative values were performed.

The software Sisvar version 5.3 was used.

\section{Results and Discussion}

\section{Chemical composition of EOs}

In the EOs of $T$. vulgaris and R. officinalis, 13 and 16 constituents were identified, respectively. In T. vulgaris, there was $28.07 \%$ of the phenylpropanoid thymol, followed 
Table 1 - Composition of edible coatings.

\begin{tabular}{lccc}
\hline \multirow{2}{*}{ Constituents } & \multicolumn{3}{c}{ Edible coatings } \\
\cline { 2 - 4 } & $\mathrm{CT}^{\mathrm{a}}$ & $\mathrm{CR}^{\mathrm{b}}$ & $\mathrm{CW}^{\mathrm{c}}$ \\
\hline Edible gelatin powder (g) & 24 & 24 & 24 \\
Sterile distilled water (part A) (mL) & 50 & 50 & 70 \\
Tween 80 at 25\% (v/v) in sterile distilled water & 30 & 30 & 30 \\
(mL) & & & \\
Sterile distilled water (part B) (mL) & 900 & 900 & 900 \\
Essential oil of Thymus vulgaris (mL) & 20 & $\mathrm{NU}^{\mathrm{d}}$ & $\mathrm{NU}^{\mathrm{d}}$ \\
Essential oil of Rosmarinus officinalis $(\mathrm{mL})$ & $\mathrm{NU}^{\mathrm{d}}$ & 20 & $\mathrm{NU}^{\mathrm{d}}$ \\
\hline
\end{tabular}

${ }^{a}$ Meat with edible gelatin coating containing essential oil Thymus vulgaris. ${ }^{\mathrm{b}}$ Meat with edible gelatin coating containing essential oil Rosmarinus officinalis. ${ }^{\mathrm{c}}$ Meat with edible gelatin coating without essential oil. ${ }^{\mathrm{d}} \mathrm{Not}$ used.

by $18.89 \%$ of para-cymene and $12.70 \%$ of linalool, both monoterpenes. For $R$. officinalis, only monoterpenes were observed as the majority constituents: 1,8-cineole (33.10\%), camphor $(19.03 \%)$, alpha-pinene $(11.55 \%)$ and beta-pinene (10.27\%) (Table 2). Dimitrijevic et al. (2007) similarly verified thymol (17.37\%), para-cymene (15.3\%) and carvacrol $(12.10 \%)$ as the majority in the EO of $T$. vulgaris. For $R$. officinalis, they found a prevalence of 1,8 -cineole $(52.20 \%)$ and camphor (10.08\%).

\section{Antilisterial activity of EOs in culture medium Dilution in agar}

In the agar dilution technique, the $\mathrm{EO}$ of $T$. vulgaris presented higher activity, with a MIC of $0.25 \%(\mathrm{v} / \mathrm{v})$ against $1.00 \%(\mathrm{v} / \mathrm{v})$ of $R$. officinalis EO. Several studies founded in the literature also reported the in vitro potential of different EOs in the control of L. monocytogenes, and, in general, what is observed is that the EOs of T. vulgaris, Cinnamomum and Cymbopogon species stand out in terms of antilisterial activity (Oliveira et al., 2012; Andrade et al., 2012, Millezi et al., 2012). A similar result to the one obtained in this study was founded by Singh et al. (2003), that also verified a lower MIC against L. monocytogenes for T. vulgaris EO in comparison with the value obtained for $R$. officinalis.

Differences in the antibacterial activity among EOs of different plant species are attributed to the chemical com-

Table 2 - Chemical composition of essential oils of Thymus vulgaris and Rosmarinus officinalis.

\begin{tabular}{|c|c|c|c|c|}
\hline \multirow[t]{3}{*}{ Constituents } & \multicolumn{4}{|c|}{ Essential oils } \\
\hline & \multicolumn{2}{|c|}{ Thymus vulgaris } & \multicolumn{2}{|c|}{ Rosmarinus officinalis } \\
\hline & $\operatorname{Tr}^{\mathrm{a}}$ & $\%^{\mathrm{b}}$ & $\operatorname{Tr}^{\mathrm{a}}$ & $\%$ \\
\hline Alpha-pinene & 10.267 & 6.16 & 10.335 & 11.55 \\
\hline Camphene & 10.797 & 3.01 & 10.804 & 3.11 \\
\hline Beta-pinene & 11.854 & 1.51 & 11.918 & 10.27 \\
\hline Myrcene & 12.462 & 2.78 & 12.462 & 1.33 \\
\hline Para-cymene & 13.854 & 18.89 & - & - \\
\hline Limonene & 13.926 & 2.61 & - & - \\
\hline 1, 8-Cineole & 14.008 & 1.40 & 14.180 & 33.10 \\
\hline Gamma-Terpinene & 15.071 & 8.70 & 15.037 & 0.81 \\
\hline Linalool & 16.683 & 12.70 & 16.613 & 1.51 \\
\hline Camphor & - & - & 18.403 & 19.03 \\
\hline Isoborneol & - & - & 19.086 & 3.34 \\
\hline Terpinen-4-ol & - & - & 19.490 & 0.82 \\
\hline Alpha-terpineol & 20.209 & 3.62 & 19.985 & 1.78 \\
\hline Bornyl acetate & - & - & 23.349 & 0.94 \\
\hline Thymol & 23.903 & 28.07 & - & - \\
\hline Carvacrol & 24.067 & 4.63 & - & - \\
\hline Eugenol & - & - & 25.757 & 0.78 \\
\hline Alpha-copaene & - & - & 26.422 & 0.54 \\
\hline $\begin{array}{l}\text { Trans } \\
\text { (beta)-caryophyllene }\end{array}$ & - & - & 27.924 & 7.63 \\
\hline Alpha-Humulene & - & - & 28.945 & 1.58 \\
\hline Caryophyllene oxide & 32.927 & 4.01 & - & - \\
\hline Total & - & 98.09 & - & 98.12 \\
\hline
\end{tabular}

${ }^{a}$ Retention time. ${ }^{b}$ The percentages represent the integration of the areas of the peaks. The numbers in bold represent the major components. 
position and the relative proportions of their individual constituents (Viuda-Martos et al., 2008). Usually, EOs that possess the stronger antibacterial properties contain high concentrations of phenolic compounds, such as carvacrol, eugenol and thymol (Burt, 2004; Dorman and Deans, 2000), the last one founded in the EO of T. vulgaris that was used in this study.

\section{Disc volatilization}

The higher activity of $T$. vulgaris was again observed. For T. vulgaris, the diameters of the inhibition zones formed on the surface of the culture medium below the filter paper disc increased linearly with the increase of EO concentration, varying from 51.46 to $67.50 \mathrm{~mm}$ (Figure 2). For the EO of R. officinalis, there was no formation of an inhibition area; however, it was possible to observe a discreet reduction of bacterial growth, especially at the highest concentration $\left(0.72 \mu \mathrm{L} . \mathrm{cm}^{-3}\right)$. The effect of the EO vapor of $T$. vulgaris against $L$. monocytogenes has already been determined in vitro by López et al. (2007) and Nedorostova et al. (2009). Regarding R. officinalis, a similar result to that obtained by López et al. (2005) was verified, who demonstrated that its vapor did not present activity against $L$. monocytogenes in culture medium.

\section{Antilisterial activity of EOs in raw beef}

\section{Edible gelatin coating}

L. monocytogenes population in the meat pieces increased linearly during the storage days independently of the treatment. However, the coatings containing EOs (CT and CR) were effective against $L$. monocytogenes inoculated in raw bovine meat at 48 hours of storage, because their medium average counts were lower than those of the control treatments $(\mathrm{CW}$ and $\mathrm{WC})(\mathrm{p}<0.05)$. The antilisterial effect of the coatings containing EOs (CT and CR) increased from the first hour of storage until the 48th; however, it decreased after 96 hours (Table 3 ). This demonstrates that, in spite of the antibacterial substance being gradually liberated from the coating and being able to in-

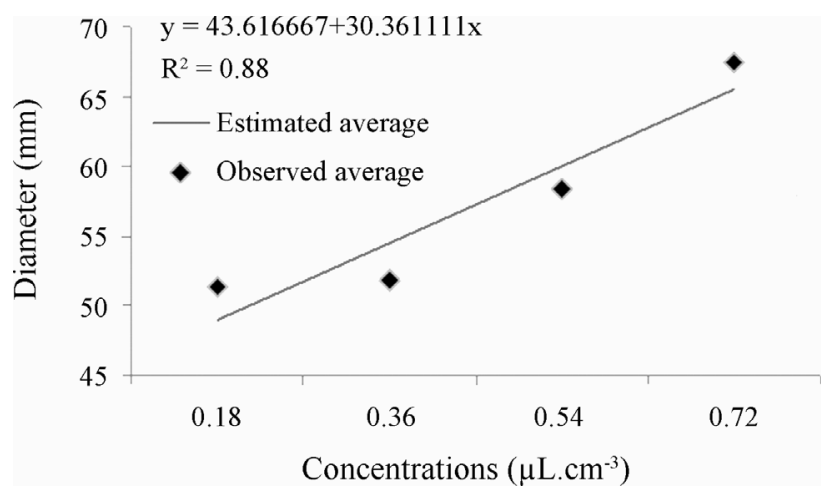

Figure 2 - Effect of the Thymus vulgaris essential oil vapor on the formation of Listeria monocytogenes inhibition zones on the culture medium surface after incubation at $37{ }^{\circ} \mathrm{C}$ for 24 hours.
Table 3 - Effect of the use of different edible gelatin coatings in the counts of Listeria monocytogenes in pieces of raw beef stored at $7{ }^{\circ} \mathrm{C}$.

\begin{tabular}{lccc}
\hline \multirow{2}{*}{$\begin{array}{l}\text { Treatments } \\
\text { applied to beef }\end{array}$} & \multicolumn{3}{c}{ Bacterial counts (Log cfu. ${ }^{-1}$ ) } \\
\cline { 2 - 4 } & 1 hour & 48 hours & 96 hours \\
\hline $\mathrm{CT}^{\mathrm{a}}$ & $4.44 \pm 0.32^{\mathrm{A}}$ & $5.00 \pm 0.22^{\mathrm{A}}$ & $5.63 \pm 1.01^{\mathrm{A}}$ \\
$\mathrm{CR}^{\mathrm{b}}$ & $4.48 \pm 0.59^{\mathrm{A}}$ & $5.04 \pm 0.22^{\mathrm{A}}$ & $5.94 \pm 1.04^{\mathrm{A}}$ \\
$\mathrm{WC}^{\mathrm{c}}$ & $5.46 \pm 0.72^{\mathrm{A}}$ & $6.13 \pm 0.66^{\mathrm{B}}$ & $5.94 \pm 1.17^{\mathrm{A}}$ \\
$\mathrm{CW}^{\mathrm{d}}$ & $5.30 \pm 1.22^{\mathrm{A}}$ & $6.25 \pm 0.42^{\mathrm{B}}$ & $6.64 \pm 0.21^{\mathrm{A}}$ \\
\hline
\end{tabular}

The values are de averages of three repetitions \pm the standard deviation. Averages followed by the same uppercase letter in the same column do not differ among themselves by the Scott-Knott test, to $5 \%$ of probability. ${ }^{a}$ Meat with edible coating of gelatin containing essential oil of Thymus vulgaris. ${ }^{b}$ Meat with edible coating of gelatin containing essential oil of Rosmarinus officinalis. ${ }^{c}$ Meat without edible gelatin coating. ${ }^{\mathrm{d}}$ Meat with edible gelatin coating without essential oil.

hibit the bacterial population that grew on the food surface, this effect only increased until 48 hours. Starting from this growth stage, L. monocytogenes in the meat was not controlled with the same efficiency. This might have occurred due to the high initial bacterial population, the psychrotrophic characteristic of this species or the presence of an adequate substrate (raw bovine meat) for its development, presenting appropriate intrinsic factors, such as water activity (0.99), $\mathrm{pH}$ (approximately 5.6) and nutrient availability (water, proteins, lipids, carbohydrates, soluble non-protein substances and vitamins) (Jay et al., 2005; Lado and Yousef, 2006; Lawrie and Ledward, 2006).

The counts of $L$. monocytogenes in the meats with CT remained slightly lower than in those with CR during the storage days. However, there was no significant difference between the average performance of CT and CR ( $p>0.05)$ (Table 3). This fact suggests that the antibacterial activity of EOs in food matrix can differ from its in vitro effect, where the $\mathrm{EO}$ of $T$. vulgaris was higher.

Even using EO concentrations above the MICs obtained in vitro in the elaboration of the coatings, they were not capable of eliminating or completely inhibiting the population of L. monocytogenes present in the meat matrix (Table 3). Some authors have demonstrated that the antibacterial effect of EOs can be reduced in the food matrix as a result of the interaction with different food components, which leads to the need for higher concentrations to reduce the bacterial population (Singh et al., 2003; Smith-Palmer et al., 2001). Furthermore, in studies conducted as challenge tests, L. monocytogenes was inoculated in the food at concentrations that, most of the time, exceeded the natural contamination levels usually found, which can decrease the effectiveness of the treatments (Neetoo et al., 2010). The microbial growth in naturally contaminated products can be significantly slower (Dalgaard and Jørgensen, 2000), and therefore, the effect of antimicrobial coatings can be more pronounced in fact than in studies where the microorganism was inoculated (Neetoo et al., 2010). 
Other studies have also verified the antibacterial action of EOs added in films or edible coatings applied in raw fish and raw bovine meat (Lu et al., 2010; Min and Oh, 2009; Ojagh et al., 2010; Oussalah et al., 2004; Zinoviadou et al., 2009), and one of them also used the EO of $T$. vulgaris (Emiroglu et al., 2010). A result similar to what we observed in regard to the control of $L$. monocytogenes was found by Gill et al. (2001), who observed that the coating of hams with gelatin gel containing $6 \%(\mathrm{v} / \mathrm{v})$ Coriandrum sativum EO emulsified with lecithin inhibited the growth of this bacterium.

\section{Vapor activity}

The population of $L$. monocytogenes exhibited a slight linear decrease during the storage period independently of submission to the EO vapors. The vapor of $T$. vulgaris EO (VT) was effective against L. monocytogenes inoculated in raw bovine meat at 96 hours of storage, because their average counts were lower than those of the control treatment $(\mathrm{WV})(\mathrm{p}<0.05)$. Notably, the effect of VT against L. monocytogenes inoculated in the meat increased with storage time, as shown by the reduction of the counts in relation to WV (Table 4). This result demonstrates that the vapor of this EO was gradually liberated, and it remained active during the entire storage time of the product. The higher antilisterial effect of T. vulgaris EO when compared with $R$. officinalis EO verified in the meat inoculation experiment was also observed in vitro, where the incubation temperature $\left(37^{\circ} \mathrm{C}\right)$ was more favorable for rapid volatilization of the compounds (Burt et al., 2007).

Skandamis and Nychas (2002) verified the increase in shelf life of raw bovine meat stored in a modified atmosphere together with filter paper squares containing Origanum vulgare EO put inside the packaging but not in contact with the meat. Burt et al. (2007) verified that carvacrol in the vapor phase was able to reduce or eliminate the population of Salmonella enterica serotype Enteritidis inoculated in raw chicken meat. However, no reports were found in the literature regarding the activity of $T$. vulgaris and $R$. officinalis EO vapors against bacteria present in

Table 4 - Effect of the submission to the vapor of the essential oils in the counts of Listeria monocytogenes in pieces of raw beef stored at $7{ }^{\circ} \mathrm{C}$.

\begin{tabular}{lccc}
\hline \multirow{2}{*}{$\begin{array}{l}\text { Treatments } \\
\text { applied to beef }\end{array}$} & \multicolumn{3}{c}{ Bacterial counts (Log cfu. $\left.{ }^{-1}\right)$} \\
\cline { 2 - 4 } & 1 hour & 48 hours & 96 hours \\
\hline $\mathrm{VT}^{\mathrm{a}}$ & $4.51 \pm 0.07^{\mathrm{A}}$ & $4.30 \pm 0.08^{\mathrm{A}}$ & $3.88 \pm 0.23^{\mathrm{A}}$ \\
$\mathrm{VR}^{\mathrm{b}}$ & $4.34 \pm 0.03^{\mathrm{A}}$ & $4.20 \pm 0.04^{\mathrm{A}}$ & $4.15 \pm 0.16^{\mathrm{B}}$ \\
$\mathrm{WV}^{\mathrm{c}}$ & $4.60 \pm 0.08^{\mathrm{A}}$ & $4.47 \pm 0.08^{\mathrm{A}}$ & $4.28 \pm 0.33^{\mathrm{B}}$ \\
\hline
\end{tabular}

The values are de averages of three repetitions \pm the standard deviation. Averages followed by the same uppercase letter in the same column do not differ among themselves by the Scott-Knott test, to $5 \%$ of probability. ${ }^{a}$ Meat subjected to the vapor of the essential oil of Thymus vulgaris. ${ }^{b}$ Meat subjected to the vapor of the essential oil of Rosmarinus officinalis. ${ }^{c}$ Meat not subjected to the vapor of essential oils. foods or the activity of EO vapors against $L$. monocytogenes inoculated in foods.

\section{Conclusions}

The two options used (edible gelatin coating and vapor activity), in spite of exercising effects with differentiated behaviors, presented antibacterial activity against $L$. monocytogenes inoculated in raw bovine meat. However, we emphasize that the greatest reductions were obtained in the experiment that evaluated the antilisterial activity of edible coatings containing EOs.

This study supplied important information regarding new and promising natural alternatives for the control of this pathogenic bacterium in the meat industry. These alternatives are based on the concept of active packaging with the use of EOs of $T$. vulgaris and R. officinalis as antibacterial agents.

We conclude that, to prove the real effectiveness and viability of these alternatives studies with naturally contaminated meat must be conducted accompanied by an assessment of the sensory acceptability of these products.

\section{Acknowledgments}

The authors would like to thank the National Council of Technological and Scientific Development (CNPq) for scholarships to the first and second authors and the Research Support Foundation of the State of Minas Gerais (FAPEMIG) for financial support.

\section{References}

Andrade MA, Cardoso MG, Batista LR, Mallet ACT, Machado SMF (2012) Essential oils of Cinnamomum zeylanicum, Cymbopogon nardus and Zingiber officinale: composition, antioxidant and antibacterial activities. Rev Ciênc Agron 43:399-408.

Bourtoom T (2008) Edible films and coatings: characteristics and properties. Int Food Res J 15:1-12.

Burt S (2004) Essential oils: their antibacterial properties and potential applications in foods-a review. Int. J Food Microbiol 94:223-253.

Burt SA, Fledderman MJ, Haagsman HP, van Knapen F, Veldhuizen EJA (2007) Inhibition of Salmonella enterica serotype Enteritidis on agar and raw chicken by carvacrol vapour. Int J Food Microbiol 119:346-350.

Chen J, Zhang X, Mei L, Jiang L, Fang W (2009) Prevalence of Listeria in Chinese Food Products from 13 Provinces Between 2000 and 2007 and Virulence Characterization of Listeria monocytogenes Isolates. Foodborne Pathog Dis 6:7-14.

Dalgaard P, Jørgensen LV (2000) Cooked and brined shrimps packed in a modified atmosphere have a shelf-life of $>7$ months at $0{ }^{\circ} \mathrm{C}$, but spoil in 4-6 days at $25^{\circ} \mathrm{C}$. Int J Food Sci Tech 35:431-442.

Devlieghere F, Vermeiren L, Debevere J (2004) New preservation Technologies: possibilities and limitations. Int Dairy $\mathrm{J}$ 14:273-285. 
Dimitrijevic SI, Mihajlovski KR, Antonovic DG, Milanovic-Stevanovic MR, Mijin DZ (2007) A study of the synergistic antilisterial effects of a sub-lethal dose of lactic acid and essential oils from Thymus vulgaris L., Rosmarinus officinalis L. and Origanum vulgare L. Food Chem 104:774-782.

Dorman HJD, Deans SG (2000) Antimicrobial agents from plants: antibacterial activity of plant volatile oils. J Appl Microbiol 88:308-316.

Emiroglu ZK, Yemis GP, Coskun BK, Candogan K (2010) Antimicrobial activity of soy edible films incorporated with thyme and oregano essential oils on fresh ground beef patties. Meat Sci 86:283-288.

Gill AO, Delaquis P, Russo P, Holley RA (2001) Evaluation of antilisterial action of cilantro oil on vacuum packed ham. Int J Food Microbiol 73:83-92.

Jay JM, Loessner MJ, Golden DA (2005) Modern Food Microbiology, Springer, New York.

Karakolev R (2009) Incidence of Listeria monocytogenes in beef, pork, raw-dried and raw-smoked sausages in Bulgaria. Food Control 20:953-955.

Lado BH, Yousef AE (2006) Characteristics of Listeria monocytogenes Important to Food Processors. In: Ruser, E.; Marth, E.H. (eds). Listeria, Listeriosis and Food Safety. CRC Press, Boca Raton, p. 157-213.

Lawrie RA, Ledward DA (2006) Lawrie's Meat Science, CRC Press, Boca Raton.

López P, Sanchez C, Batle R, Nerin C (2005) Solid- and vapor-phase antimicrobial activities of six essential oils: Susceptibility of selected foodborne bacterial and fungal strains. J Agr Food Chem 53:6939-6946.

López P, Sanchez C, Batle R, Nerin C (2007) Vapor-Phase Activities of Cinnamon, Thyme, and Oregano Essential Oils and Key Constituents against Foodborne Microorganisms. J Agr Food Chem 55:4348-4356.

Lu F, Ding Y, Ye X, Liu D (2010) Cinnamon and nisin in alginate-calcium coating maintain quality of fresh northern snakehead fish fillets. $L W T$ - Food Sci Tech 43:1331-1335.

Millezi AF, Caixeta DS, Rossoni DF, Cardoso MG, Piccoli RH (2012) In vitro antimicrobial properties of plant essential oils Thymus vulgaris, Cymbopogon citratus and Laurus nobilis against five important foodborne pathogens. Ciênc Tecnol Aliment 32:167-172.

Min BJ, Oh JH (2009) Antimicrobial Activity of Catfish Gelatin Coating Containing Origanum (Thymus capitatus) Oil against Gram-Negative Pathogenic Bacteria. J Food Sci 74:143-148.

Mor-Mur M, Yuste J (2010) Emerging Bacterial Pathogens in Meat and Poultry: An Overview. Food Bioprocess Tech 3:24-35.

Nedorostova L, Kloucek P, Kokoska L, Stolcova M, Pulkrabek J (2009) Antimicrobial properties of selected essential oils in vapour phase against foodborne bacteria. Food Control 20:157-160.

Neetoo H, Ye M, Chen H (2010) Bioactive alginate coatings to control Listeria monocytogenes on cold-smoke salmon slices and fillets. Int J Food Microbiol 136:326-331.
Ojagh SM, Rezaei M, Razavi SH, Hosseini SMH (2010) Effect of chitosan coatings enriched with cinnamon oil on the quality of refrigerated rainbow trout. Food Chem 120:193-198.

Oliveira MMM, Brugnera DF, Alves E, Piccoli RH (2010) Biofilm formation by Listeria monocytogenes on stainless steel surface and biotransfer potential. Braz J Microbiol 41:91-106.

Oliveira MMM, Brugnera DF, Cardoso MG, Alves E, Piccoli RH (2010) Disinfectant action of Cymbopogon sp. essential oils in different phases of biofilm formation by Listeria monocytogenes on stainless steel surface. Food Control 21:549-553.

Oliveira MMM, Brugnera DF, Nascimento JÁ, Piccoli RH (2012) Control of planktonic and sessile bacterial cells by essential oils. Food Bioprod. Process. http://dx.doi.org/10.1016/j.fbp.2012.03.002.

Oussalah M, Caillet S, Salmiéri S, Saucier L, Lacroix M (2004) Antimicrobial and antioxidant effects of milk protein-based film containing essential oils for the preservation of whole beef muscle. J Agr Food Chem 52:5598-5605.

Pandit VA, Shelef LA (1994) Sensitivity of Listeria monocytogenes to rosemary (Rosmarinus officinalis L.). Food Microbiol 11:57-63.

Pesavento G, Ducci B, Nieri D, Comodo N, Lo Nostro A (2010) Prevalence and antibiotic susceptibility of Listeria spp. isolated from raw meat and retail foods. Food Control 21:708713.

Singh A, Singh RK, Bhunia AK, Singh N (2003) Efficacy of plant essential oils as antimicrobial agents against Listeria monocytogenes in hotdogs. Lebensmittel- Wissenschaft undTechnologie 36:787-794.

Skandamis PN, Nychas GJE (2002) Preservation of fresh meat with active and modified atmosphere packaging conditions. Int J Food Microbiol 79:35-45.

Smith-Palmer A, Stewart J, Fyfe L (2001) The potential application of plant essential oils as natural food preservatives in soft cheese. Food Microbiol 18:463-470.

Sofos JN (2008) Challenges to meat safety in the 21st century. Meat Science 78:3-13.

Solomakos N, Govaris A, Koidis P, Botsoglou N (2008) The antimicrobial effect of thyme essential oil, nisin, and their combination against Listeria monocytogenes in minced beef during refrigerated storage. Food Microbiol 25:120-127.

Tajkarimi MM, Ibrahim SA, Cliver DO (2010) Antimicrobial herb and spice compounds in food. Food Control 21:11991218.

Ustunol Z (2009) Edible Films and Coatings for Meat and Poultry. In: Embuscado, M.E.; Huber, K.C. (eds). Edible Films and Coatings for Food Aplications. Springer, New York, p. 245-268.

Viuda-Martos M, Ruiz-Navajas Y, Fernandez-Lopez J, PerezAlvarez P (2008) Antibacterial activity of different essential oils obtained from spices widely used in Mediterranean diet. Int J Food Sci Tech 43:526-553.

Zinoviadou K, Koutsoumanis KP, Biliaderis CG (2009) Physicochemical properties of whey protein isolate films containing oregano oil and their antimicrobial action against spoilage flora of fresh beef. Meat Science 82:338-345.

All the content of the journal, except where otherwise noted, is licensed under a Creative Commons License CC BY-NC. 